\title{
Reference Values for Cardiopulmonary Exercise Testing in Young Male Slovak Athletes
}

Filip Olekšák ${ }^{1}$ Pavol Dvoran, ${ }^{1,}$, L'ubica Jakušová1, Peter Ďurdík ${ }^{1}$, Matúš Igaz¹, Peter Bánovčin ${ }^{1}$

\section{ABSTRACT}

Background: The reference values of young athletes for cardiopulmonary exercise testing are lacking. Expert opinions encourage production of local values specific for certain population.

Patients and methods: The study population consisted of 136 healthy male caucasian athletic children and adolescents coming from one specific football school in northern Slovakia. Exercise testing with continuous electrocardiography was performed, and ventilatory parameters, oxygen uptake $\left(\mathrm{VO}_{2}\right)$, and carbon dioxide $\left(\mathrm{CO}_{2}\right)$ production were measured continuously with a respiratory gas analysis system. Results: Peak $\mathrm{VO}_{2}$ max $/ \mathrm{kg}$ was changing very little across the childhood, whereas the peak work rate, heart rate and $\mathrm{O}_{2}$ Pulse were. Linear regression analysis showed a significant effect of age on $\mathrm{VE} / \mathrm{VCO}_{2}$.

Conclusion: This work provides a reference values for the most important cardiopulmonary variables that can be obtained during cardiopulmonary exercise testing in athletic children.

\section{KEYWORDS}

cardiopulmonary exercise testing; reference values; athletic children

\section{AUTHOR AFFILIATIONS}

${ }^{1}$ Clinic for children and adolescents, University Hospital Martin, Jessenius Medical Faculty in Martin, Commenius University in Bratislava, Slovakia

* Corresponding author: Clinic for children and adolescents, University hospital Martin, Slovakia; Jessenius medical faculty in Martin, Commenius University in Bratislava, Kollárova 2, 03659 Martin, Slovakia; e-mail: pavoldvoran@gmail.com

Received: 4 November 2020

Accepted: 3 March 2021

Published online: 30 July 2021

Acta Medica (Hradec Králové) 2021; 64(2): 119-124

https://doi.org/10.14712/18059694.2021.20

(c) 2021 The Authors. This is an open-access article distributed under the terms of the Creative Commons Attribution License (http://creativecommons.org/licenses/by/4.0), which permits unrestricted use, distribution, and reproduction in any medium, provided the original author and source are credited. 


\section{INTRODUCTION}

Stress tests are among the most popular non-invasive diagnostic methods in cardiological evaluation and evaluation of functional capacity of the organism. In the paediatric population, cardiopulmonary exercise testing (CPET) is considered valid but neglected diagnostic tool whose indications and location in the clinical setting are still pending for proper application (14). Adding the function of evaluation of expired air to regular stress test we get a direct insight into the functioning of oxygen transport from air to mitochondria and also into its metabolism in the body directly under stress. The way and rate of response of the organism to increasing bout of exercise can be applied in clinical practice not only to evaluate the functional parameters of athletes but also to correctly interpret the risk stratification in patients with congenital or acquired heart, lung, muscle or metabolic diseases (12). Growing amount of information about this examination and its relevance to clinical practice could become a starting point for its more frequent application in paediatric practice.

Regular pre-participation examinations in athletes should consist of physical examination and 12 lead ECG. Preparticipation screenings are meant to prevent sudden cardiac deaths (3). Athletes (in paediatrics their parents) very often ask for more thorough examination in order to gain more information about the state of their health. CPET is ideal tool to evaluate whole body state of health as it is golden standard among examinations documenting aerobic fitness of an individual.

Cardiopulmonary exercise testing differs in many aspects from the tests performed in adults (2). Results gained by CPET are dependent on the will to perform and on motivation of examined patient. To be able to evaluate one's health and level of functional capacity certain level of exhaustion must be achieved. Young athletes are much more often highly motivated, and performance results gained from their examinations are above any reference values for populations of non-athletes. On the other hand, their other than performance results are very similar to healthy non-athletes. As the physiological responses to exercise change during growth and development, appropriate paediatric reference values are essential for an adequate interpretation of the cardiopulmonary exercise test (14). Some parameters yielded from CPET in athletes of young age are incomprehensible due to lack of reference values and clinical implications. Reference values for CPET parameters may change over time and should be regularly updated or validated (14). Considering prognostic value of CPET in many diseases we can anticipate same use of this tool in training process of young athletes. Data provided by CPET might be of high value in screening for unknown underlying disease that might be aggravated by strenuous exercise.

Normal values for CPET are already published and represent a set of normal values for specific population coming from specific region with different anthropometric and cultural characteristics (16). For an adequate interpretation of CPET, the normal range of variety of CPET parameters is essential. In many studies, however, only mean or median value for the population is provided. Expert review (14) recommends reporting lower and upper limit of normal. The use of $80 \%$ of predicted as lower limit of normal should be abandoned. Instead, a Z-score should be used with a lower and upper limit of normal of $-1.96 \mathrm{SD}$ and $+1.96 \mathrm{SD}$, respectively (14).

\section{METHODS}

The study population consisted of 136 healthy male Caucasian athletic children and adolescents coming from one specific football school in northern Slovakia (Table 1). They were recruited as healthy male athletic population of children and adolescents. Athletes were examined prospectively in the period between July 2018 and December 2019. We excluded all children with a history of acute illness within 3 weeks, history of chronic disease or smoking. Every athlete underwent spirometry (Geratherm Respiratory GmbH, Germany), 12 lead ECG (BTL Cardiopoint, Czech Republic) and orthostatic blood pressure test (Omron M3, Japan) and only those with physiological findings were included. All of the athletes were highly active individuals with professional coaching, exercising for more than two hours more than 3 times a week. All children came to the hospital by car, or they came by bike or walking if their residence was within 10 min away from the hospital. Patients were informed to consume light meal at latest 1 hour before testing and to come properly hydrated.

Tab. 1
\begin{tabular}{|l|l|l|l|}
\hline Age group & \multicolumn{1}{|c|}{$\mathbf{8 - 1 0}$} & \multicolumn{1}{|c|}{$\mathbf{1 1 - 1 4}$} & \multicolumn{1}{c|}{$\mathbf{1 5 - 1 9}$} \\
\hline Age & $9.7 \pm 1.5$ & $12.5 \pm 2$ & $16.3 \pm 2.3$ \\
\hline Height & $140.9 \pm 11.3$ & $155.0 \pm 18.9$ & $178.0 \pm 13.3$ \\
\hline Weight & $31.0 \pm 8.3$ & $41.0 \pm 17.8$ & $67.0 \pm 13.2$ \\
\hline BMI & $16.2 \pm 2.4$ & $17.4 \pm 3.6$ & $20.8 \pm 3.3$ \\
\hline BSA & $1.1 \pm 0.2$ & $1.4 \pm 0.4$ & $1.8 \pm 0.2$ \\
\hline n & 46 & 48 & 42 \\
\hline
\end{tabular}

CPET was performed in upright position using treadmill (ITAM ERT-100, Poland) with breath-by-breath respiratory gas analysis (Geratherm Respiratory $\mathrm{GmbH}$, Germany). Subjects breathed through a face mask of appropriate size and through a low impedance turbine volume transducer for measurement of expiratory volume and expiratory gas concentrations. CPET results were interval averaged (every $30 \mathrm{~s}$ ), reported peak value represents mean value of all data collected during the final stage (if longer at least $30 \mathrm{~s})$. CPET was performed with the personalized incremental ramp protocol to maximal exhaustion which was achieved between the 8th and 12th minute of exercise (6). The blood pressure was measured every three minutes until peak exercise and then every 2 minutes until full recovery. All participants were verbally encouraged to exercise to exhaustion. Cut-off values for maximal exertion were established as RER greater than 1.10, breathing rate more than $40 / \mathrm{min}$ and/or plateau in oxygen consumption. Before testing all equipment was calibrated according to the instructions of the manufacturer. 
Resting HR was measured after at least $3 \mathrm{~min}$ in supine position before exercise testing and was calculated as number or RR intervals on ECG over 1 minute. Heart rate was measured by continuous 12-lead ECG during resting, warm up, peak exercise and recovery phase. Peak HR (HRpeak) was defined as the highest HR achieved during exercise. HR was recorded at 1 . and 2. min after cessation of the exercise, and HR recovery (HRR1, HRR2) was calculated as the difference between HRpeak and the HR in first and second minute. $\mathrm{VO}_{2}$ max is defined as plateau in oxygen consumption with increase less than $2 \mathrm{ml} / \mathrm{kg} / \mathrm{min}$ with increase of $10 \%$ work rate (6). $\mathrm{VO}_{2}$ peak is then defined as the highest achieved $\mathrm{VO}_{2}$ in settings of not achieving $\mathrm{VO}_{2} \max$ and is calculated as the mean of two highest consecutive values of 15 -s averages of $\mathrm{VO}_{2}(2)$. The $\mathrm{VE} / \mathrm{VCO}_{2}$ slope was obtained by linear regression analysis of whole measured dataset of exercise data before achieving respiratory compensation point. Peak work rate (WRpeak) was measured in absolute values and as weight adjusted value. The point of initiation of anaerobic metabolism (anaerobic threshold AT, ventilatory anaerobic threshold VAT) is defined as nonlinear elevation in production of $\mathrm{CO}_{2}$ to consumption of $\mathrm{O}_{2}$. $\mathrm{VO}_{2}$ vs WR $\left(\Delta \mathrm{VO}_{2} / \Delta \mathrm{WR}\right)$ was measured as the slope obtained by linear regression analysis of $\mathrm{VO}_{2}(\mathrm{~mL} / \mathrm{min})$ versus WR (W). For ventilatory parameters we obtained minute ventilation, tidal volume, breathing frequency and breathing reserve (BR) at AT and peak exercise.

\section{STATISTICS}

Statistical analysis was performed with SPSS 26.0 (SPSS, Inc., Chicago, Illinois, USA). Values are presented as mean values and mean values \pm 1.96 standard deviation. The effect of age on the measured parameters was determined by linear regression analysis.

\section{RESULTS}

We examined 136 boys with an age range $8-18$. Subject characteristics are shown in Table 1. In order to obtain clear data capable of direct use we divided study group into subgroups according to age. Results are presented as mean value and lower and upper limit using 1.96 SD (standard deviation). We provide data that has been measured resting on treadmill, at AT and peak exercise. All participants performed CPET without complications and were able to adhere to chosen protocol. Table 2 presents CPET data and Table 3 presents regression equations for chosen parameters. There were no noted ECG abnormalities during exercise testing. According to our findings resting heart rate $(71 / \mathrm{min}$ vs. $65 / \mathrm{min}$ vs. $61 / \mathrm{min}$ ) and peak heart rate $(190 / \mathrm{min}$ vs. $188 / \mathrm{min}$ vs. $180 / \mathrm{min}$ ) declined with age in highly active children. (Figure 3) On the other hand, resting $\mathrm{O}_{2}$ Pulse $(2.22 \mathrm{ml} /$ beat vs. $2.68 \mathrm{ml} /$ beat vs. $3.99 \mathrm{ml} /$ beat) and peak $\mathrm{O}_{2}$ Pulse ( $8.27 \mathrm{ml} /$ beat vs. $11.62 \mathrm{ml} /$ beat vs. $19.41 \mathrm{ml} /$ beat) raised with age. Resting breathing rate remained unchanged during whole childhood (19/min vs. $19 / \mathrm{min}$ vs. $18 / \mathrm{min})$ whereas resting tidal volume and minute ventilation raised. $\mathrm{VO}_{2} \max$ raised with age $(48.29 \mathrm{ml} / \mathrm{min} / \mathrm{kg}$ vs. $51 \mathrm{ml} / \mathrm{min} / \mathrm{kg}$ vs.
$52.81 \mathrm{ml} / \mathrm{min} / \mathrm{kg})$. $\mathrm{VO}_{2} / \mathrm{WR}$ remained unchanged with age $(10.28 \mathrm{ml} / \mathrm{min} / \mathrm{W}$ vs. $10.20 \mathrm{ml} / \mathrm{min} / \mathrm{W}$ vs. $10.32 \mathrm{ml} / \mathrm{min} / \mathrm{W})$. $\mathrm{VE} / \mathrm{VCO}_{2}$ as a marker of ventilatory effectivity declined with age (31.0 vs. 28.8 vs. 26.6). $\mathrm{VO}_{2}$ and $\% \mathrm{VO}_{2}$ of $\mathrm{VO}_{2} \max$ in AT remained stable across the childhood. WRpeak/kg (as hallmark of exercise tolerance) were growing steadily with age ( $4.15 \mathrm{~W} / \mathrm{kg}$ vs. $4.50 \mathrm{~W} / \mathrm{kg}$ vs. $4.87 \mathrm{~W} / \mathrm{kg}$ ) (Figure 1).

Tab. 2

\begin{tabular}{|c|c|c|c|}
\hline Age group & $8-10$ & $11-14$ & $15-18$ \\
\hline $\begin{array}{l}\text { Number } \\
\text { of patients }\end{array}$ & $n=46$ & $\mathrm{n}=48$ & $n=42$ \\
\hline HR rest & 71 & 65 & 61 \\
\hline $\pm 1.96 \mathrm{SD}$ & $(50-92)$ & $(45-85)$ & $(43-79)$ \\
\hline $\mathrm{O}_{2}$ Pulse rest & 2.22 & 2.68 & 3.99 \\
\hline $\pm 1.96 \mathrm{SD}$ & $(0.65-3.78)$ & $(0.94-4.41)$ & $(1.68-6.30)$ \\
\hline VE rest & 7.09 & 8.50 & 11.00 \\
\hline $\pm 1.96 \mathrm{SD}$ & $(1.65-12.52)$ & $(3.63-13.37)$ & $(3.61-18.39)$ \\
\hline BF rest & 19 & 19 & 18 \\
\hline $\pm 1.96 \mathrm{SD}$ & $(11-27)$ & $(11-28)$ & $(9-27)$ \\
\hline Vt rest & 0.39 & 0.44 & 0.67 \\
\hline $\pm 1.96 \mathrm{SD}$ & $(0.08-0.70)$ & $(0.16-0.72)$ & $(0.11-1.23)$ \\
\hline WR peak & 134.9 & 193.9 & 320.6 \\
\hline $\pm 1.96 \mathrm{SD}$ & $(89.8-180)$ & $(103.1-284.8)$ & $(239-402.3)$ \\
\hline WR peak/kg & 4.15 & 4.50 & 4.87 \\
\hline $\pm 1.96 \mathrm{SD}$ & $(3.45-4.84)$ & $(3.76-5.23)$ & $(4.33-5.41)$ \\
\hline $\mathrm{VO}_{2} \max$ (abs.) & 1.55 & 2.18 & 3.48 \\
\hline $\pm 1.96 \mathrm{SD}$ & $(0.90-2.21)$ & $(1.18-3.19)$ & $(2.43-4.53)$ \\
\hline $\mathrm{VO}_{2} \max / \mathrm{kg}$ & 48.29 & 51.00 & 52.81 \\
\hline $\pm 1.96 \mathrm{SD}$ & $(32.31-64.27)$ & $(38.37-63.62)$ & $(42.21-63.41)$ \\
\hline RER & 1.15 & 1.17 & 1.16 \\
\hline $\pm 1.96 \mathrm{SD}$ & $(0.98-1.33)$ & $(0.96-1.37)$ & $(0.97-1.35)$ \\
\hline$\Delta \mathrm{VO}_{2} / \Delta \mathrm{WR}$ & 10.28 & 10.20 & 10.32 \\
\hline $\pm 1.96 \mathrm{SD}$ & $(6.76-13.80)$ & $(7.25-13.15)$ & $(7.66-12.98)$ \\
\hline VE peak & 61.6 & 81.6 & 122.5 \\
\hline $\pm 1.96 \mathrm{SD}$ & $(33.0-90.2)$ & $(35.8-127.3)$ & $(72.0-173.0)$ \\
\hline BF peak & 58 & 54 & 52 \\
\hline $\pm 1.96 \mathrm{SD}$ & $(41-76)$ & $(42-66)$ & $(34-70)$ \\
\hline Vt peak & 1.06 & 1.51 & 2.37 \\
\hline $\pm 1.96 \mathrm{SD}$ & $(0.55-1.56)$ & $(0.72-2.31)$ & $(1.48-3.27)$ \\
\hline BR peak & 19.65 & 22.63 & 25.93 \\
\hline $\pm 1.96 \mathrm{SD}$ & $(0-45.97)$ & $(0-48.87)$ & $(0-54.43)$ \\
\hline HR peak & 190 & 188 & 180 \\
\hline $\pm 1.96 \mathrm{SD}$ & $(166-213)$ & $(169-206)$ & $(156-204)$ \\
\hline HRR1 & 39 & 31 & 21 \\
\hline $\pm 1.96 \mathrm{SD}$ & $(4-84)$ & $(1-60)$ & $(6-49)$ \\
\hline HRR2 & 66 & 62 & 47 \\
\hline $\pm 1.96 \mathrm{SD}$ & $(37-85)$ & $(27-98)$ & $(15-79)$ \\
\hline $\mathrm{O}_{2}$ Pulse peak & 8.27 & 11.62 & 19.41 \\
\hline \pm 1.96 SD & $(5.18-11.37)$ & $(6.02-17.22)$ & $(13.37-25.45)$ \\
\hline
\end{tabular}




\begin{tabular}{|c|c|c|c|}
\hline Age group & $8-10$ & $11-14$ & $15-18$ \\
\hline Sys BP peak & 134 & 137 & 156 \\
\hline $\pm 1.96 \mathrm{SD}$ & $(107-161)$ & $(104-170)$ & $(127-185)$ \\
\hline Dia BP peak & 71 & 75 & 74 \\
\hline \pm 1.96 SD & $(53-89)$ & $(56-93)$ & $(56-92)$ \\
\hline VE/VCO 2 slope & 31.0 & 28.8 & 26.6 \\
\hline $\pm 1.96 \mathrm{SD}$ & $(24.9-37.0)$ & $(23.5-34.1)$ & $(22.3-30.9)$ \\
\hline PET $\mathrm{CO}_{2}$ peak & 34 & 36 & 40 \\
\hline \pm 1.96 SD & $(29-39)$ & $(30-41)$ & $(33-46)$ \\
\hline Vd/Vt peak & 14.2 & 14.9 & 12.0 \\
\hline $\pm 1.96 \mathrm{SD}$ & $(7.5-20.9)$ & $(10.6-19.1)$ & $(7.1-16.8)$ \\
\hline $\mathrm{VO}_{2}$ at $\mathrm{AT}$ abs. & 0.94 & 1.34 & 2.05 \\
\hline $\pm 1.96 \mathrm{SD}$ & $(0.40-1.47)$ & $(0.58-2.11)$ & $(1.20-2.90)$ \\
\hline $\mathrm{VO}_{2}$ at AT $/ \mathrm{kg}$ & 29.07 & 31.33 & 31.13 \\
\hline $\pm 1.96 \mathrm{SD}$ & $(13.06-44.07)$ & $(17.24-45.42)$ & $(20.84-42.42)$ \\
\hline$\% \mathrm{VO}_{2}$ at $\mathrm{AT}$ & 61 & 62 & 59 \\
\hline \pm 1.96 SD & $(35-62)$ & $(37-88)$ & $(39-79)$ \\
\hline RER at AT & 0.86 & 0.87 & 0.82 \\
\hline $\pm 1.96 \mathrm{SD}$ & $(0.68-1.04)$ & $(0.72-1.01)$ & $(0.65-0.99)$ \\
\hline HR at AT & 145 & 144 & 136 \\
\hline \pm 1.96 SD & $(109-182)$ & $(105-183)$ & $(106-165)$ \\
\hline $\mathrm{O}_{2}$ Pulse at AT & 6.49 & 9.34 & 15.18 \\
\hline \pm 1.96 SD & $(3.18-9.81)$ & $(4.56-14.11)$ & $(9.68-20.68)$ \\
\hline VE at AT & 26.5 & 36.4 & 48.4 \\
\hline $\pm 1.96 \mathrm{SD}$ & $(9.2-43.9)$ & $(12.3-60.5)$ & $(24.3-72.5)$ \\
\hline BF at AT & 38 & 34 & 30 \\
\hline $\pm 1.96 \mathrm{SD}$ & $(20-57)$ & $(21-47)$ & $(15-45)$ \\
\hline BR at AT & 64 & 66 & 70 \\
\hline $\pm 1.96 \mathrm{SD}$ & $(40-89)$ & $(45-87)$ & $(54-86)$ \\
\hline $\mathrm{VE} / \mathrm{VCO}_{2}$ at $\mathrm{AT}$ & 27.1 & 27.7 & 26.3 \\
\hline $\pm 1.96 \mathrm{SD}$ & $(22.5-31.7)$ & $(23.4-31.9)$ & $(22.3-30.2)$ \\
\hline WR at AT & 69.4 & 102.8 & 181.3 \\
\hline \pm 1.96 SD & $(28.6-110.2)$ & $(31.9-173.6)$ & $(91.9-270.7)$ \\
\hline $\mathrm{Vd} / \mathrm{Vt}$ at $\mathrm{AT}$ & 10.09 & 13.14 & 12.32 \\
\hline \pm 1.96 SD & $(0.08-20.11)$ & $(5.03-21.26)$ & $(5.24-19.40)$ \\
\hline
\end{tabular}

Tab. 3

\begin{tabular}{|l|c|}
\hline \multicolumn{1}{|c|}{ Parameter } & \multicolumn{1}{c|}{ Regression equation } \\
\hline WRpeak & $y=0.1024 \times($ age $)+3.1829$ \\
\hline VE $/ \mathrm{VCO}_{2}$ & $\mathrm{y}=-0.6604 \times($ age $)+37.27$ \\
\hline HR rest & $\mathrm{y}=-1.4176 \times($ age $)+204.11$ \\
\hline HR peak & $\mathrm{y}=-1.5485 \times($ age $)+85.57$ \\
\hline $\mathrm{O}_{2}$ Pulse & $\mathrm{y}=1.5403 \times($ age $)-6.9403$ \\
\hline $\mathrm{VO}_{2}$ max/kg & $\mathrm{y}=0.596 \times($ age $)+43.009$ \\
\hline
\end{tabular}

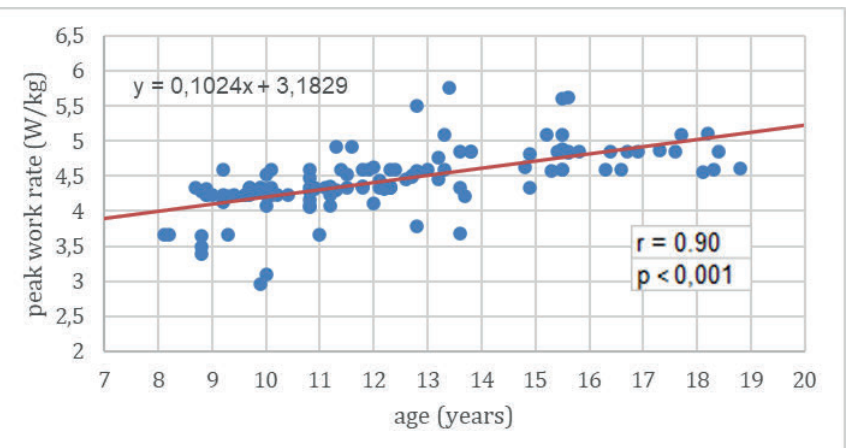

Fig. 1 The relation between age and the maximal work rate. The trendline represents linear regression of all data.

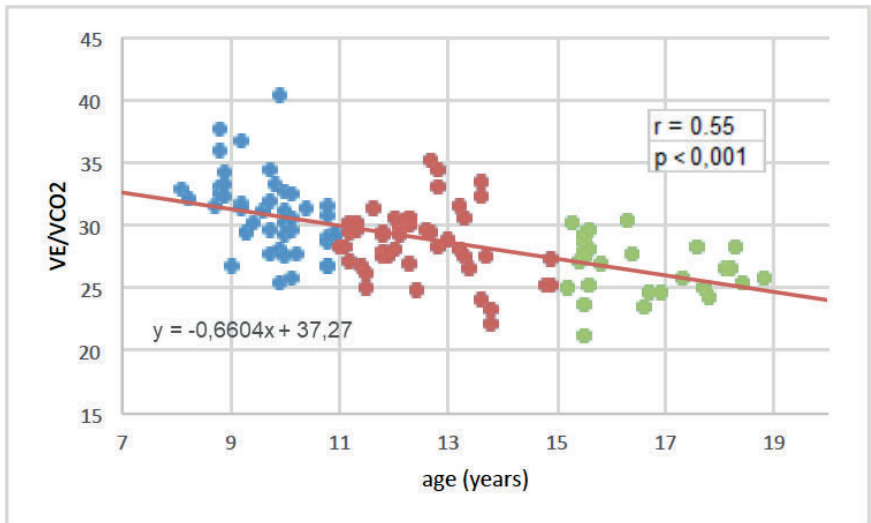

Fig. 2 The relation between age and the ventilation to carbon dioxide exhalation $\left(\mathrm{VE} / \mathrm{VCO}_{2}\right)$ slope. The trendline represents linear regression of all data.

$\mathrm{HR}$ rest, resting heart rate (beats $/ \mathrm{min}) ; \mathrm{O}_{2}$ Pulse rest ( $\mathrm{ml} /$ beat); $V E$ rest, resting minute ventilation (l/min); $B$ rest, breathing rate $(1 / \mathrm{min})$; Vt rest, resting tidal volume (l); WR peak, peak work rate (W); WR peak $/ \mathrm{kg}$, peak work rate per $\mathrm{kg}$ (W/kg); $\mathrm{VO}_{2}$ max abs., absolute maximal oxygen uptake (l/min); $\mathrm{VO}_{2} \mathrm{max} / \mathrm{kg}$, oxygen uptake per $\mathrm{kg}(\mathrm{ml} / \mathrm{min} / \mathrm{kg}) ; \mathrm{RER}$, respiratory exchange ratio (1); $\Delta \mathrm{VO}_{2} /$ $\triangle W R$, slope of work rate $(\mathrm{W})$ to oxygen uptake $(\mathrm{ml} / \mathrm{min})$; VE peak, peak minute ventilation (l); BF peak, peak breathing rate (1); Vt peak, peak tidal volume (l); BR peak, peak breathing reserve $(\%)$; HR peak, peak heart rate $(1 / \mathrm{min})$; HRR1 - hear rate recovery in 1 minute $(1 / \mathrm{min}) ;$ HRR2 - heart rate recovery in 2 minute ( $1 / \mathrm{min})$; O2Pulse peak (ml/beat); Sys BP peak, peak systolic pressure $(\mathrm{mmHg})$; Dia BP peak, peak diastolic pressure $(\mathrm{mmHg}) ; \mathrm{VE} / \mathrm{VCO}$ slope, slope of respiratory minute ventilation to $\mathrm{CO}_{2}$ production; $\mathrm{PET} \mathrm{CO}_{2}$ peak $(\mathrm{mmHg}) ; \mathrm{Vd} / \mathrm{Vt}$ peak, peak dead space ventilation (\%); $\mathrm{VO}_{2}$ at AT abs., absolute oxygen uptake at anaerobic threshold (l/min); $\mathrm{VO}_{2}$ at $\mathrm{AT} / \mathrm{kg}$, oxygen uptake at anaerobic threshold per $\mathrm{kg}(\mathrm{ml} / \mathrm{min} / \mathrm{kg}) ; \% \mathrm{VO}_{2}$ at AT, percentage of maximal oxygen uptake in anaerobic threshold (\%); RER at AT, respiratory exchange ratio at anaerobic threshold; HR at AT (1), heart rate at anaerobic threshold (1/min), $O_{2}$ Pulse at AT $(\mathrm{ml} /$ beat); VE at AT, minute ventilation at anaerobic threshold (l/min); BF at AT, breathing rate at anaerobic threshold (1/min); BR at AT, breathing reserve at anaerobic threshold (\%); VE/VCO at at, slope of respiratory minute ventilation to $\mathrm{CO}_{2}$ production; WR at AT, work rate at anaerobic threshold $(\mathrm{W}) ; \mathrm{Vd} / \mathrm{Vt}$ at $\mathrm{AT}$, dead space ventilation at anaerobic threshold (\%).

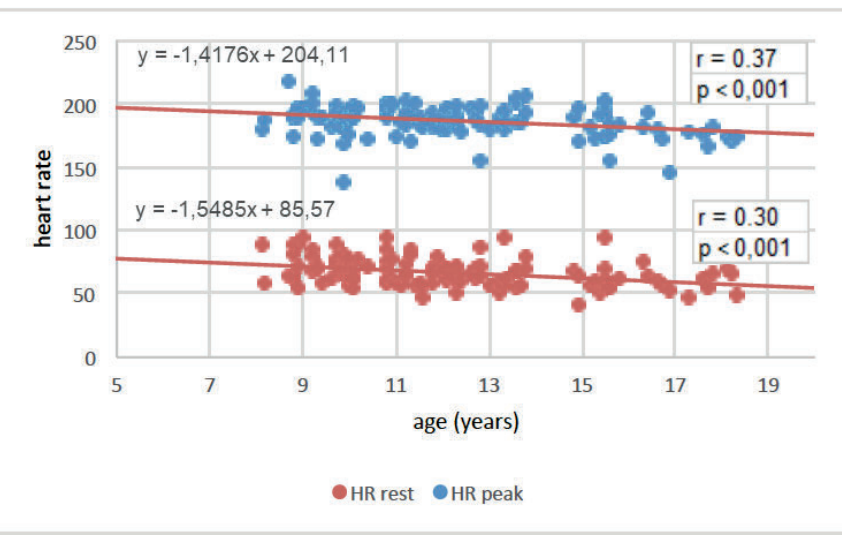

Fig. 3 The relation between age and resting heart rate (HR rest). The trendline represents linear regression of all data. The relation between age and peak heart rate (HR peak). The trendline represents linear regression of all data. 


\section{DISCUSSION}

The primary aim of this study was to provide reference values for cardiopulmonary exercise testing in the cohort of healthy athletic children between 8 and 18 years of age. Data yielded are presented in Table 2. Upper and lower limit for age dependent variables are given for all 3 age groups which makes it possible to use these values as reference data.

$\mathrm{VE} / \mathrm{VCO}_{2}$ slope was decreasing steadily with age (Figure 2). Decrease in $\mathrm{VE} / \mathrm{VCO}_{2}$ slope with advancing age has been explained by a slightly lower pressure of $\mathrm{CO}_{2}$ set point during exercise in the younger children and higher breathing efficiency in older children (larger tidal volumes and a relatively lower breathing frequency) $(9,16)$.

$\mathrm{VO}_{2} / \mathrm{WR}$ remains unchanged with age. Calculation of the steepness of this slope is a valid measurement of $\mathrm{O}_{2}$ flow or utilization in the exercising tissues (5). Our findings correlate with Harkel et al. (15). but our value was approximately $10.2 \mathrm{ml} \mathrm{O}_{2} / \mathrm{min}$ per $\mathrm{W}$ in contrast of theirs $9.5 \mathrm{ml} \mathrm{O} / \mathrm{min}$ per $\mathrm{W}$ in cohort very similar in account of age distribution. On the other hand, in our cohort we examined athletes where athlete's body adaptation might lead to processes which higher muscle efficiency in $\mathrm{O}_{2}$ utilisation. Lower values are present in patients with impaired $\mathrm{O}_{2}$ delivery to the exercising muscles such as patients with cardiac defects or malnourished patients.

During a progressive exercise test, the anaerobic threshold occurs when aerobic metabolism is insufficient to meet energy requirements. The AT indicates the highest oxygen uptake that can be sustained during exercise without developing lactic acidosis. The ability to sustain a high fractional utilization of athlete's maximal oxygen uptake $\left(\% \mathrm{VO}_{2} \mathrm{max}\right)$ in $\mathrm{AT}$ is considered crucial in order to maximize exercise effect. Anaerobic threshold is highly correlated to the distance running performance as compared to maximum aerobic capacity or $\mathrm{VO}_{2} \max$, because sustaining a high fractional utilization of the $\mathrm{VO}_{2} \max$ for a long time delays the metabolic acidosis (4). It is not affected by patient effort or motivation and may be determined on a submaximal exercise test (2). $\mathrm{VO}_{2}$ at AT is useful submaximal parameter in children. It is a good indicator of exercise capacity in children who are unable to perform to maximal exhaustion (12). The $\mathrm{VO}_{2}$ at $\mathrm{AT}$ is a highly reproducible measure that provides insight into aerobic exercise capacity of children (13). Published data on normal values of $\mathrm{VO}_{2}$ at $\mathrm{AT}$ are abundant but ranging from $45 \%$ to $75 \%$ of $\mathrm{VO}_{2} \max (10,18)$. Most recent study by Harkel et al. (16). reported $66 \%$ of $\mathrm{VO}_{2} \max$ in children of age 8 and 9 and $60 \%$ of $\mathrm{VO}_{2}$ max in older children which is consistent with our findings (59-62\%).

Peak $\mathrm{VO}_{2}\left(\mathrm{VO}_{2} \max \right)$ kept rising throughout childhood with only very small inclination (Figure 5). Aerobic fitness is one of the most important components of physical fitness (15). The measurement of maximal $\mathrm{VO}_{2} \max$ or $\mathrm{VO}_{2}$ peak during a progressive cardiopulmonary exercise test up to maximal exertion is widely considered the gold standard for assessing aerobic fitness (1). Comparing reference values for age in boys (16). with young athletes, boys of same age that are not athletes have lower $\mathrm{VO}_{2} \max$ than athletes of same age. This states as a proof that regular exercise lead to increase in one's aerobic fitness even in children.

The maximum or peak HR achieved declined with age in all studies. Although in paediatric patients peak HR seems to remain constant throughout the paediatric years (11). We observed slight decline in peak HR in adolescents which is explainable with regular exercise that leads to athletic HR adaptation (Figure 3 ).

$\mathrm{O}_{2}$ Pulse $\left(\mathrm{VO}_{2} / \mathrm{HR}\right)$ can be used as an indirect indicator of cardiac stroke volume (17). A plateau in the $\mathrm{O}_{2}$ Pulse at a low value implies limited cardiac output, either because of heart disease or disorders of the pulmonary circulation (7). The measurement of $\mathrm{O}_{2}$ Pulse during exercise can provide insight into the change in stroke volume during progressive exercise by assessing pattern of $\mathrm{O}_{2}$ Pulse changes in exercise and by estimating the value at peak exercise. (13). Recent study showed good correlation between $\mathrm{O}_{2}$ Pulse and stroke volume in adult patients undergoing CPET (8). In our cohort $\mathrm{O}_{2}$ Pulse was rising during examination from rest, throughout whole exercise until it reached plateau and was rising with age (Figure 4).

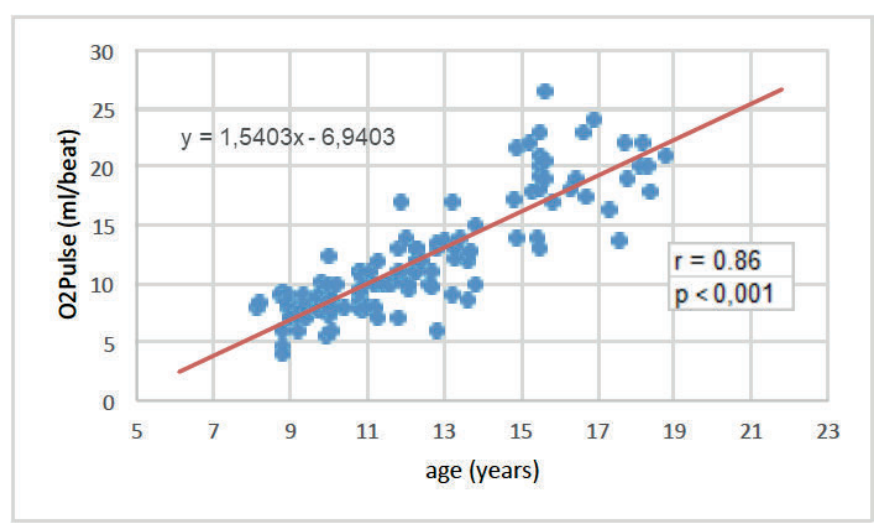

Fig. 4 The relation between age and peak $\mathrm{O}_{2}$ Pulse. The trendline represents linear regression of all data.

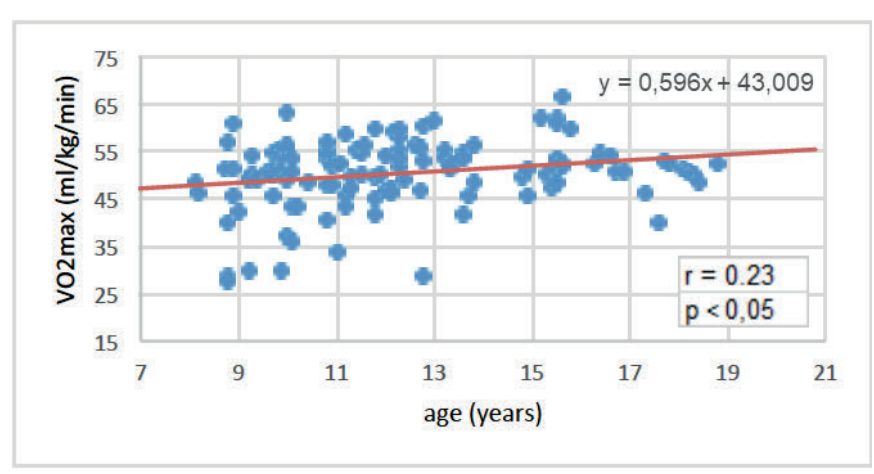

Fig. 5 The relation between age and $\mathrm{VO}_{2}$ max. The trendline represents linear regression of all data.

\section{LIMITATIONS}

Our dataset presents only male athletes reference values and is set to specific population of athletes competing in single sport. Reference values might be suitable for other types of athletes (as we found changes in CPET parameters 
that are expected in highly active individuals) but confirmation from specific population locally is missing.

\section{CONCLUSION}

This work comprehensively provides a reference set of data for the most important cardiopulmonary variables that can be obtained during exercise testing in young athletes in Slovakia. Our work was set in specific population as these reference values are lacking. We found that many obtained other than performance parameters are not altered by regular exercise as they are showing physiological functions of body systems and are comparable with healthy inactive children. Performance results $\left(\mathrm{VO}_{2} \max\right.$, WRpeak) were growing with age and were higher than in children of same age that are not athletes.

\section{CONFLICT OF INTEREST}

No conflict of interest to declare.

\section{FUNDING}

Work was supported by VEGA grant 1/0310/18.

\section{REFERENCES}

1. American Thoracic Society; American College of Chest Physicians. ATS/ACCP Statement on cardiopulmonary exercise testing. Am J Respir Crit Care Med 2003; 167: 211-77.

2. Dilber D, Malčić I, Ćaleta T, Zovko A. Reference values for cardiopulmonary exercise testing in children and adolescents in northwest Croatia. Paediatria Croatica 2015; 59(4): 195-201.
3. Fritsch P, Dalla Pozza R, Ehringer-Schetitska D, et al. Cardiovascular pre-participation screening in young athletes: recommendations of the association of European paediatric cardiology. Cardiology in the Young 2017; 27(9): 1655-60.

4. Ghosh AK. Anaerobic threshold: its concept and role in endurance sport. The Malaysian Journal of Medical Sciences: MJMS 2004; 11(1): 24.

5. Groen WG, Hulzebos EH, Helders PJ, Takken T. Oxygen uptake to work rate relationship during exercise in children with lung, heart or muscle disease. Int J Sports Med 2010; 31: 202-6.

6. Karila C, de Blic J, Waernessyckle S, Benoist, MR, Scheinmann, P. Cardiopulmonary exercise testing in children: an individualized protocol for workload increase. Chest 2001; 120(1): 81-7.

7. Kinnear W, Blakey J. A Practical Guide to the Interpretation of Cardio-Pulmonary Exercise Tests. Oxford University Press, 2014.

8. Evangelista M, Alfonzetti E, Bandera F, Guazzi M. O2-pulse measure obtained by gas exchange analysis is an accurate esteeme of stroke volume?. Europ Heart J 2019; 40(Suppl 1): ehz745.0787.

9. Nagano Y, Baba R, Kuraishi K, et al. Ventilatory control during exercise in normal children. Ped Res 1998; 43: 704-7.

10. Ohuchi H, Nakajima T, Kawade M, Matsuda M, Kamiya T. Measurement and validity of the ventilatory threshold in patients with congenital heart disease. Pediatr Cardiol 1996; 17(1): 7-14.

11. Paridon SM, Bricker JT. Quantitative QRS changes with exercise in children and adolescents. Med Sci Sports Exerc 1990; 22(2): 159-64.

12. Reybrouck T, Gewillig M. Exercise testing in congenital heart disease. In: Armstrong $\mathrm{N}$ and Van Mechelen $\mathrm{W}$ (eds) Paediatric exercise science and medicine. 2nd ed. Oxford: Oxford University Press, 2008, pp. 421-30.

13. Rowland TW. American College of Sports Medicine. Cardiopulmonary exercise testing in children and adolescents. Human Kinetics, 2017.

14. Takken T, Mylius CF, Paap D, et al. Reference values for cardiopulmonary exercise testing in healthy subjects - an updated systematic review. Expert Rev Cardiovasc Ther 2019; 17(6), 413-26.

15. Takken T, Bongers BC, Van Brussel M, Haapala EA, Hulzebos EH. Cardiopulmonary exercise testing in pediatrics. Ann Am Thorac Soc 2017; 14(Suppl 1): S123-S128.

16. Ten Harkel AD, Takken T. Normal values for cardiopulmonary exercise testing in children. Eur J Cardiovasc Prev Rehabil 2011; 18(4): 676-7.

17. Unnithan V, Rowland TW. Use of oxygen pulse in predicting Doppler-derived maximal stroke volume in adolescents. Pediatr Exerc Sci 2015; 27(3): 412-8.

18. Washington RL, van Gundy JC, Cohen C, Sondheimer HM, Wolfe RR. Normal aerobic and anaerobic exercise data for North American school-age children. J Pediatr 1988; 112(2): 223-33. 